\title{
Physico-chemical and enzymatic changes in peach (Prunus persica (L.) Batsch) fruit in response to sodium salts during low temperature storage
}

\author{
S. K. Jawandha*, P. P. S. Gill, Annu Verma and Navdeep Kaur \\ Department of Fruit Science, Punjab Agricultural University, Ludhiana-141004 (Punjab), INDIA \\ ${ }^{*}$ Corresponding author. E-mail: skjawandha@pau.edu
}

Received: March 13, 2016; Revised received: August 26, 2016; Accepted: November 15, 2016

\begin{abstract}
Shan-i-Punjab' is a leading cultivar of peach (Prunus persica (L.) Batsch) in Punjab. After harvesting peach fruits cannot be stored for a longer period under ambient conditions. To prolong the post-harvest life of fruits, an experiment was conducted during the year 2014. Physiological mature fruits of peach cv. Shan-i-Punjab were harvested and subjected to various post-harvest dip treatments viz. sodium bicarbonate (@ 0.5 and $1 \%$ ), sodium benzoate (@ 0.5 and 1\%) for 5 mins. Treated and untreated (control) fruits were packed in Corrugated fibre board CFB boxes and kept under low temperature storage conditions $\left(0-1^{0} \mathrm{C}\right.$ and $\left.90-95 \% \mathrm{RH}\right)$ for 6 weeks. Stored fruits were analyzed for various physico-chemical characteristics after 2, 4, 5 and 6 weeks of storage. Fruits treated with $0.5 \%$ sodium bicarbonate showed better results in terms low PLW (5.05\%), high palatability rating (7.66), TSS $(11.26 \%)$, acidity $(0.70 \%)$ and PME activity $(1.28 \mathrm{ml}$ of $0.02 \mathrm{~N} \mathrm{NaOH}$ used) upto 4 weeks of storage as compared to control. It can be concluded that peach fruits of the cultivar Shan-i-Punjab treated with sodium bicarbonate @ 0.5\% can be safely stored upto 4 weeks with acceptable quality under low temperature conditions.
\end{abstract}

Keywords: Peach, PME, Sodium benzoate, Sodium bicarbonate, Storage

\section{INTRODUCTION}

Peach is an important stone fruit of the temperate region but its low chill varieties can also be grown successfully under sub-tropical conditions of Punjab. Shan -i-Punjab, Early Grande, Florda Prince, Prabhat and Pratap are the commercial varieties of peach grown in the state. Among these varieties 'Shan $-\mathrm{i}-\mathrm{Punjab}$ ' is widely accepted by the growers due to its better size, colour, texture and juicy pulp. Fruits of this cultivar ripen in the summer month (May). High temperature and low humidity during this period leads to rapid transpiration and deterioration of fruits under ambient conditions. Moreover, due to miss handling and lack of proper storage and transport facilities a significant amount of produce is wasted. Hence, there is need to standardize the technology to improve the storage life of peach fruits, reduce the post harvest losses and regulate the market. Shelf life of fruits can be extended by optimization of environmental conditions, minimization of mechanical damage, application of food additives, edible coatings and ionizing radiations (Serrano et al., 2004). A considerable extension in storage life of many fruits has been reported by the use of postharvest chemicals ranging from fungicides and fumigants to antioxidants and GRAS (generally recognized as safe) chemicals. The role of bicarbonate and benzoate salts was also studied by Usall et al., (2008) who reported that the bicarbonate and benzoate salts reduces the post harvest decay due to their considerable anti- microbial activities with a minimal risk of injury to the fruit. Moreover, Sodium bicarbonate is a very attractive alternative because it is readily available and has little risk of phytotoxicity at the low concentrations (14\%) (Palou et al., 2001). Therefore, the present study was conducted to investigate the role of sodium bicarbonate and sodium benzoate to maintain the quality and extend the post harvest life of peach $c v$. Shan-iPunjab under low temperature storage conditions (0$1{ }^{\circ} \mathrm{C}$ and $\left.90-95 \% \mathrm{RH}\right)$.

\section{MATERIALS AND METHODS}

The research experiment was conducted during the year 2014 in Post Harvest Laboratory, Department of Fruit Science, Punjab Agricultural University, Ludhiana. Physiological mature fruits were hand harvested from Fruit Research Farm and immediately transferred to the Post Harvest Laboratory of the Department for storage studies. Misshappened, bruised and soft textured fruits were discarded before application of treatments. Selected fruits were washed in running tap water to remove any dust or spray residues and air dried in shade. These fruits were immersed in aqueous solutions of $0.5 \%$ sodium bicarbonate, $1.0 \%$ sodium bicarbonate, $0.5 \%$ sodium benzoate, $1.0 \%$ sodium benzoate for 5 mins and control fruits were kept untreated. All treated and untreated fruits were packed in corrugated fiber board boxes and kept in cold chamber at $0-1^{\circ} \mathrm{C}$ and $90-95 \% \mathrm{RH}$ for six weeks. Stored fruits were ana- 
lyzed for physiological loss in weight (PLW), palatability rating (PR), total soluble solids (TSS), acidity, and pectin methyl esterase (PME) activity after interval of 2, 4, 5 and 6 weeks of storage. Percent physiological loss in weight was calculated by recording difference between initial weight $\left(\mathrm{w}_{\mathrm{i}}\right)$ and final fruit weight $\left(\mathrm{w}_{\mathrm{f}}\right)$, as per formula PLW $(\%)=\mathrm{w}_{\mathrm{i}}-\mathrm{w}_{\mathrm{f}} / \mathrm{w}_{\mathrm{i}} \times 100$. The juice of fruit was extracted and filtered through muslin cloth and TSS was estimated using digital refractometer (ATAGO, Japan), placing 1-2 drops of juice on the prism of refractometer. The readings were corrected with help of temperature correction chart at $20^{\circ} \mathrm{C}$. Titratable acidity was estimated by titrating 2 $\mathrm{ml}$ of strained juice of fruits against $0.1 \mathrm{~N} \mathrm{NaOH}$ solution using phenolphthalein as an indicator and was expressed as percentage. Pectin methyl esterase activity was estimated by using the method given by Mahadevan and Sridhar (1982). Experimental fruits were rated for palatability (PR) by a panel of four judges at each storage interval using nine point

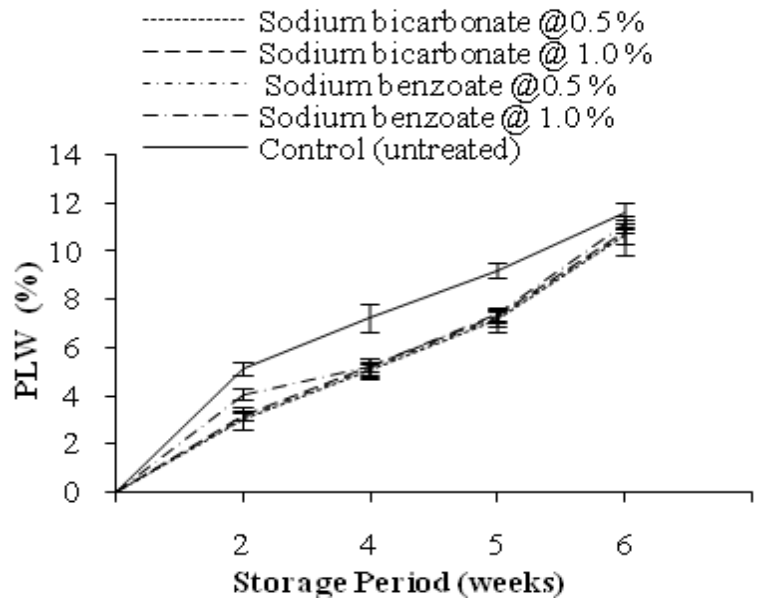

Fig. 1. Effect of post-harvest treatments on PLW of peach fruits during storage. Vertical bars represent $\pm S$.E of mean.

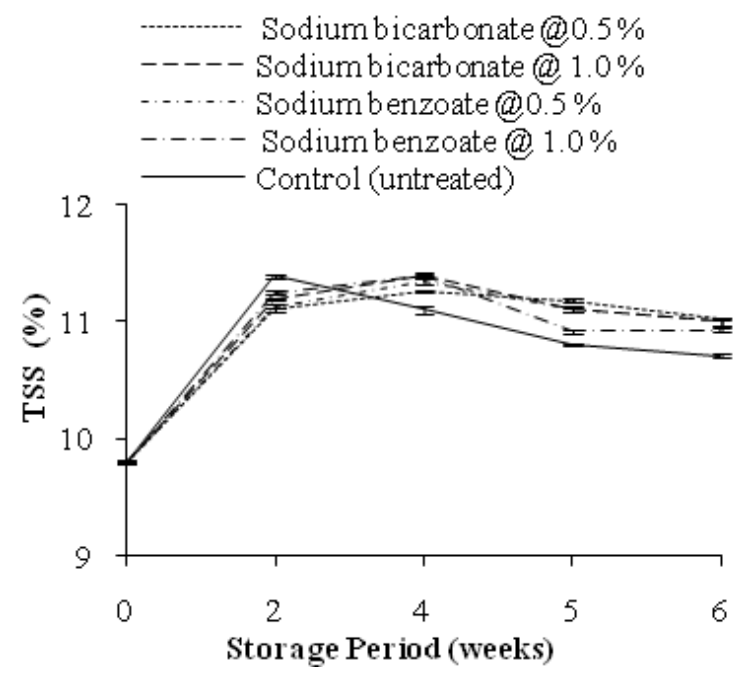

Fig. 3. Effect of post-harvest treatments on TSS of peach fruits during storage. Vertical bars represent $\pm S$.E of mean.
'Hedonic Scale' described by Amerine et al. (1965).

Statistical analysis: Two factor experiment was laid out in a completely randomized block design (Factorial) with four replications and data were analyzed for Analysis of Variance (Proc GLM) using statistical package SAS 9.3 (The SAS system for Windows, Version 9.3, SAS Institute, Cary, NC). Results were expressed as mean \pm SE using Fischer's LSD test at $\mathrm{p}<0.05$.

\section{RESULTS AND DISCUSSION}

Results of the present study showed the loss in weight of fruits increased with advancement of storage period in all treatments including control (Fig. 1). This increase in PLW might be due to an increase in respiration, ripening and evapo-transpiration processes during storage. Fruits dipped in sodium bicarbonate @ $0.5 \%$ showed lowest weight loss as compared to other treatments followed by sodium benzoate@0.5\% treat-

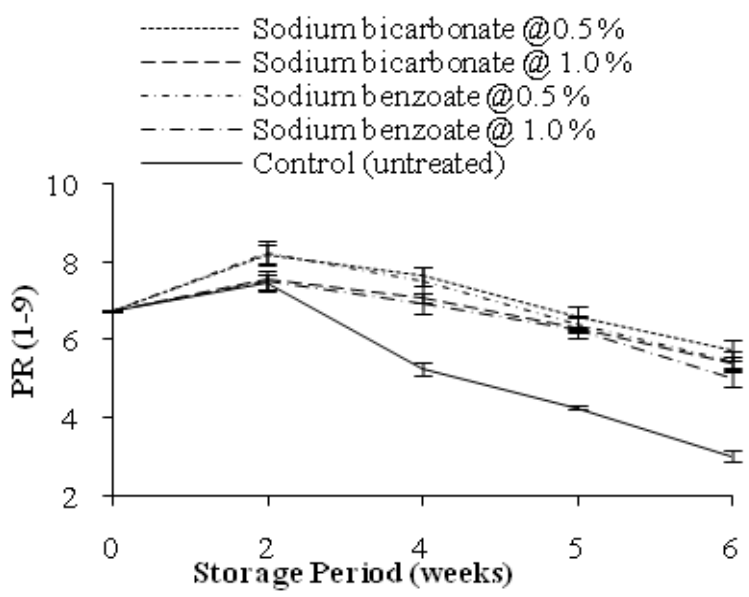

Fig. 2. Effect of post-harvest treatments on $P R$ of peach fruits during storage. Vertical bars represent \pm S.E of mean.

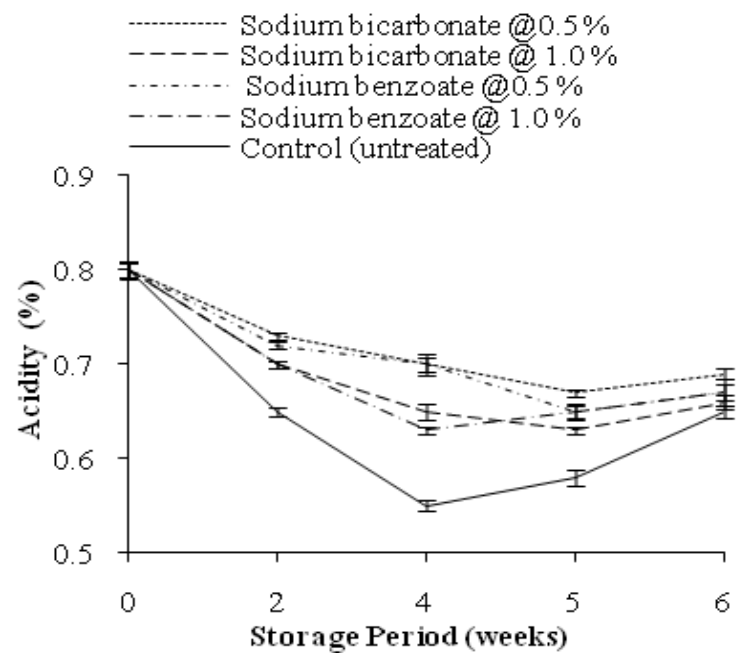

Fig. 4. Effect of post-harvest treatments on Acidity of peach fruits during storage. Vertical bars represent \pm S.E of mean. 


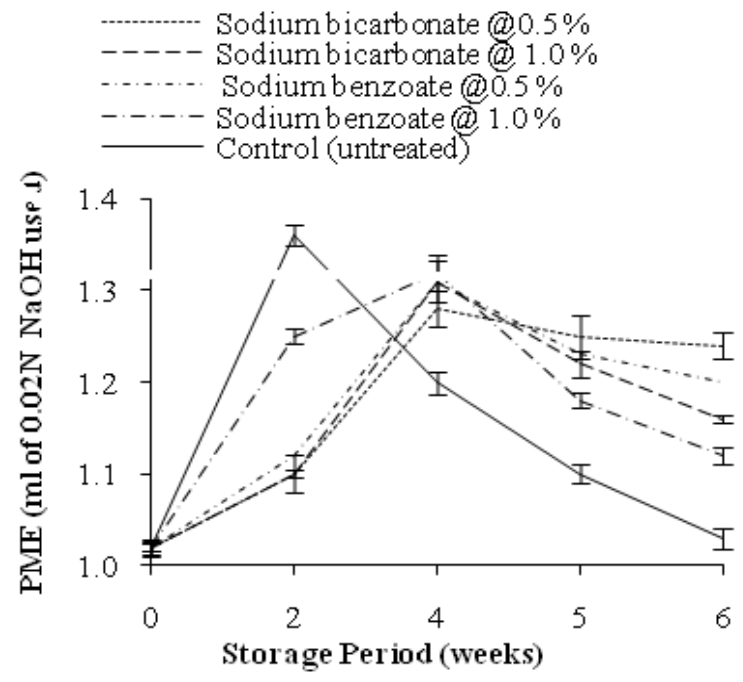

Fig. 5. Effect of post-harvest treatments on PME of peach fruits during storage. Vertical bars represent $\pm S$.E of mean.

ment. The reduction in weight loss by sodium benzoate was also reported by Bhagwan et al. (2000) for tomato in Hyderabad. Maximum weight loss recorded in control fruits during entire period of study indicated the role of sodium salts in lowering the weight loss in fruits during cold storage. Moreover, lower doses of sodium bicarbonate and sodium benzoate (@0.5\%)were found to be more effective in lowering weight loss in fruits than at its higher doses (@1\%).

Data revealed that palatability rating improved significantly $(p<0.05)$ upto 2 weeks of storage in all the treatments but after that a reduction in rating was recorded (Fig.2). The initial improvement in palatability rating was due to ripening of fruits during storage. At the later stages of storage, the decline in palatability rating (PR) represents the deterioration of quality during storage. The highest palatability rating after 4,5 and 6 weeks of storage was recorded in $0.5 \%$ sodium bicarbonate treated fruits, followed by $0.5 \%$ sodium benzoate treatment and the lowest was noticed in control (untreated) fruits. Results were in accordance with findings of Antunes et al. (2008) of University of Algarne, Portugal who reported that $1 \%$ sodium bicarbonate gave better results on preserving fruit quality characteristics in Breba fig fruits $c v$. Lampa Preta. At Cairo University of Egypt, Ahmed et al. (2007) reported that the Blood orange fruits were strongly influenced by sodium bicarbonate applications and stored in a good quality for 42 days. It was also reported that sodium bicarbonate was a substitute to fungicides or chemical materials used in controlling injuries and fruits deteriorations during storage. Similarly, Kader et al., (2011) at National Research Centre, Giaza, Egypt reported that grapefruits treated with carnauba wax containing sodium benzoate successfully inhibited the fungal decay and provided a long protection to treated fruits during storage.
Results related to the effect of sodium salts on total soluble solids of the peach fruit under low temperature storage (fig.3) showed an increase in TSS content of fruits which was followed by a decrease with the advancement of the storage period. An increase in TSS content was recorded upto 2 weeks of storage in control fruits whereas, in treated fruits the increase was recorded upto 4 weeks of storage and afterwards, a decline was recorded in all the treatments. However, after 6 weeks of storage, maximum TSS content was recorded in lower doses of sodium bicarbonate $0.5 \%$ followed by sodium benzoate $0.5 \%$ treated fruits and the minimum TSS content was recorded in control fruits. The increase in SSC content during storage might be due to the hydrolysis of starch into sugars and moisture loss and thereafter, decline may be ascribed to the reason that on complete hydrolysis of starch, no further increase in SSC occur and consequently a decline in SSC is expected as they are the primary substrates for respiration (Wills et al., 1980). Similarly, Antunes et al. (2008) at Portugal reported that 1\% sodium bicarbonate dip for two minutes reduced the accumulation of total soluble solids in fig fruits.

Effect of different treatments on acid content of stored peach fruits is presented in (Fig.4). A decline in acidity was recorded in fruits treated with sodium benzoate $1 \%$ and untreated fruits upto 4 weeks of storage whereas; in other treatments this decline was recorded upto 5 weeks of storage. At the end of storage, an increase in acidity was recorded in all the treatments but maximum was recorded in fruits treated with sodium bicarbonate@0.5\%. The decrease in acidity during the initial period of storage might be due to the utilization of organic acids as respiratory substrate as reported by Echeverria and Valich (1989) and by conversion of acids into sugars. An increase in acidity at the end of storage might be due to the fermentation which indicates the deterioration of fruit quality (Jawandha et al., 2014).

Pectin methyl esterase (PME) is an enzyme responsible for fruit softening during storage. The PME activity increases during ripening of fruits. Fig.5 depicts that PME activity increased upto $4^{\text {th }}$ week of storage except control fruits, where it was increased only upto 2 weeks. After 6 weeks of storage, maximum PME activity was recorded in sodium bicarbonate@0.5\% treated fruits followed by sodium benzoate @0.5\%. An increase in enzyme activity with advancement of storage period might be due to the increase in availability of substrates by hydrolysis of starch into sugars and the reduction in PME activity at the later stages of storage represents a decline in substrate availability due to the utilization of sugars in various metabolic processes. A high PME activity in treated fruits at later stages as compared to control fruits is the result of high substrate level for PME activity in treated fruits, which were already decomposed to higher extent at the early 
stages of storage in control fruits. Similar results were reported by Jawandha et al. (2012) at Punjab Agricultural University, Ludhiana who reported that ber fruits treated with $\mathrm{GA}_{3}(60 \mathrm{ppm})$ maintained the higher PME activity than control after 30 days of storage.

\section{Conclusion}

Fruits treated with sodium bicarbonate@0.5\% maintained the acceptable sensory quality rating upto 4 weeks of storage with low physiological loss in weight and high total soluble solids, acidity and PME activity as compared to control.

\section{ACKNOWLEDGEMENTS}

Authors are highly thankful for the financial support provided by the University Grant Commission - New Delhi thorough the project.

\section{REFERENCES}

Ahmed, D., Hafez, M., Hafez, O.M. and Fouad, A.A. (2007). Sodium bicarbonate application as an alternative control of postharvest decay of blood orange fruits. Res. $J$. Agric. Bio. Sci., 3: 753-759

Amerine, M.A., Pangborn, R.M. and Roessler, E.B. (1965). Principles of sensory evaluation of food. Food Science and Technology Monographs, Academic Press, New York, pp 338-339

Antunes, M.D.C., Costa, P., Miguel, M.G., Martins, D., Neves, M.A., Martins, M.A. and Gomes, C. (2008). The effect of postharvest treatments with sodium bicarbonate or acetic acid on storage ability and quality of fig fruit. Acta. Hort., 798: 279-284

Bhagwan, A., Reddy, Y.N., Rao, P.V. and Mohankumar, K.C. (2000). Shelf life extension of tomato fruits by postharvest antioxidant application. J. Appl. Hort., 2: 88
$-91$

Echeverria, E. and Valich, J. (1989). Enzymes of sugars and acid metabolism in stored 'Valencia Oranges'. J. Am. Soc. Hortic. Sci., 114: 445-449

Jawandha, S.K., Gupta, N. and Randhawa, J.S. (2012). Effect of post-harvest treatments on enzyme activity and quality of cold stored ber fruit. Not. Sci. Biol., 4: 86-89

Jawandha, S.K., Gill, P.P.S., Verma, A. and Kaur, N. (2014). Effect of coatings on storage quality of pear. Int. J. Sci. Nat., 5: 703-706

Kader, M.A., Mougy, N.E. and Lashin, S. (2011). Evaluation of grapefruit coating with chemical preservative as control measure against post harvest decay. The Polish Phytopathological Society, Poznan Phytopathologia, 59: $25-38$

Mahadevan, A. and Sridhar, R. (1982). Methods in physiological plant pathology. Sivagami Publishers, Madras.

Palou, L., Smilanick, J.L., Usall, J. and Vinas, I. (2001). Control of postharvest blue and green molds of oranges by hot water, sodium carbonate, and sodium bicarbonate. Plant Disease, 85: 371-376

Serrano, M., Romero, D.M., Zuzunaga, M., Riquelme, F. and Valero, D. (2004). Post harvest treatment and technology. Production practices and quality assessment of food crops (Eds.: R. Dris and S.M. Jain), Kluwer Academic Publishers, Netherlands, pp 55-68

Usall, J., Smilanick, J., Palou, L., Denis-Arrue, N., Teixido, N., Torres, R. and Vinas, I. (2008). Preventive and curative activity of combined treatments of sodium carbonates and Pantoea agglomerans CPA-2 to control postharvest green mold of citrus fruit. Postharvest Biol. Technol., 50: 1-7

Wills, R.B.H., Cambridge, P.A. and Scott, K.J. (1980). Use of flesh firmness and other objective tests to determine consumer acceptability of Delicious apples. Aust. J. Exp. Agric. Anim. Husb., 20: 252-256 